\title{
Ecomundi: un recurso lúdico para la enseñanza de las ciencias en Educación Infantil
}

\author{
Miriam Lara Estepa, Alicia Fernández Oliveras y María Luisa Oliveras. Universidad de \\ Granada \\ $\square$ \\ Recepción: 12 de abril de 2015 | Revisión: 30 de mayo de 2015 | Aceptación/Publicación: 24 de julio de 2015 \\ Correspondencia: mle93@correo.ugr.es | alilia@ugr.es | oliveras@ugr.es | http://hdl.handle.net/10481/37116
}

\begin{abstract}
Resumen: Este artículo resume el proceso seguido para diseñar y elaborar un recurso lúdico destinado a la enseñanza de las ciencias en Educación Infantil. Las características finales del juego creado se recogen en dos fichas modelo que podrían emplearse en el archivo de una ludoteca. Los contenidos científicos que se pretende aproximar mediante este recurso lúdico están relacionados con la fauna perteneciente a ecosistemas con características distintas: selva, bosque, desierto y tundra. Entre los fundamentos teóricos del juego original se encuentran parte de las ideas de María Montessori, concretamente, el ensayo-error como método de aprendizaje.
\end{abstract}

Palabras clave: Didáctica de las Ciencias Experimentales | Formación del profesorado | Educación Infantil | Juegos Educativos

\section{ECOMUNDI: A PLAYFUL RESOURCE FOR SCIENCE TEACHING IN EARLY CHILHOOD EDUCATION}

\begin{abstract}
This article summarizes the process used to design and develop a playful resource for the teaching of science in early childhood education. The final features of the game created are described on two different index cards that could be used in the file of an educational play centre. The scientific content we aim to introduce through this playful resource is related to the fauna belonging to ecosystems with different characteristics: jungle, forest, desert and tundra. Among the theoretical backgrounds of the original game, some of Maria Montessori's ideas are included, specifically trial and error as a learning method.
\end{abstract}

Keywords: Science Education | Teacher Training | Early Childhood Education | Educational Games

\section{Introducción}

Si bien son cada vez más los centros de educación no formal que proliferan en las ciudades y sus proximidades, entre los recursos de los que disponen no siempre se encuentran juegos educativos que presten atención a temas relacionados con las ciencias y que estén adaptados a las edades correspondientes a Educación Infantil. Aunque los docentes en formación se muestran proclives a combinar juego y ciencia infantil (Fernández-Oliveras y Oliveras, 2014b, 2015) y en sus en los proyectos incluyen, por ejemplo, propuestas lúdicas sobre educación ambiental y para la salud (Marín y Romero, 2013), en los centros educativos de esta etapa, la enseñanza de las ciencias en aún queda relegada a un segundo plano. En este sentido, consideramos de crucial importancia el diseño y la elaboración de juegos o recursos lúdicos cuyo fin sea aproximar contenidos científicos a los niños, antes de su Educación Primaria.

Seguidamente se expone el proceso seguido para diseñar y elaborar un recurso lúdico destinado a la enseñanza de las ciencias en Educación Infantil. Las características finales del juego creado se recogen en dos tipos de fichas que podrían emplearse en el archivo de una ludoteca, cuyos modelos se desarrollaron en una asignatura optativa del Grado en Maestro de Educación Infantil de la Universidad de Granada (FernándezOliveras y Oliveras, 2014a). Los contenidos científicos que se pretende aproximar mediante este recurso lúdico están relacionados con la fauna perteneciente a ecosistemas con características distintas: selva, bosque, desierto y tundra. Entre los fundamentos teóricos del juego original se encuentran parte de las ideas de María Montessori, concretamente, el ensayo-error como método de aprendizaje. 


\section{DISEÑO DEL JUEGO}

La idea principal fue que los niños supiesen distinguir la fauna de cada uno de los ecosistemas, por esta razón, se realizaría un tablero donde se representaran los distintos hábitats. Los cuatros ecosistemas distintos (tundra ártica, desierto, bosque mediterráneo y selva amazónica) estarían separados por medio de una carretera dividida en pequeñas casillas, donde los niños tendrían que realizar unas pruebas en grupo. El grupo ganador es el que tiene más pruebas conseguidas. Porque ambos grupos, ganen o pierdan la prueba, avanzarían a la siguiente casilla. Ya que en el caso contrario, de que los niños se estanquen en una casilla y no avancen en varios turnos se provocaría el desinterés del grupo en el juego. El esquema de la idea inicial del juego se recoge en la Figura 1.

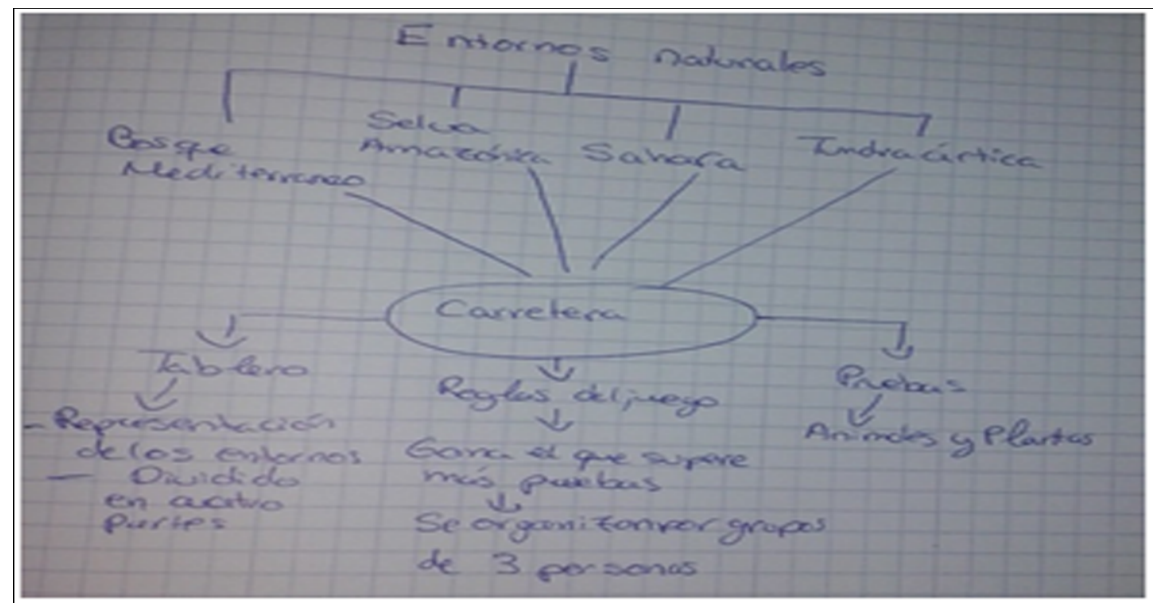

Figura 1. Esquema de la idea inicial del juego propuesto.

\section{ELABORACIÓN}

El proceso de elaboración constituye el tiempo en que se fabricó el recurso didáctico y los pasos que se han de seguir para su confección, desde la elección de los materiales al inicio, hasta su finalización. Dentro de este proceso se especificarán los materiales manejados para la elaboración del recurso didáctico.

Los materiales usados para la creación del recurso didáctico son: Cartón piedra, "Goma eva", Forro de fieltro de distintos colores, Cartulinas y fotos, Plastilina, Silicona fría, Pintura acrílica y Velcro.

Para el proceso de construcción se cortaron con un cúter 4 piezas distintas con formas de engranajes, a modo de puzle para que encajaran con otras piezas. Posteriormente las piezas cortadas que se forraron con los fieltro de distintos color (blanco, amarillo marrón y verde) y se pegaron con silicona fría. Cada uno de estos colores se asoció a un hábitat distinto (tundra ártica, desierto, bosque mediterráneo y selva amazónica, respectivamente).

Una vez terminado el tablero, se hizo la carretera con piezas independientes rectangulares de cartón piedra y se forró con fieltro gris, para que estas se unieran, se pegó cada una de las partes con velcro, para adherirse al tablero del juego. Los adornos del juego, son bolas de polietileno las cuales se pintaron con pintura acrílica para dar forma a las dunas del Sahara. Para simular un pino se cortó un trozo rectangular de cartulina y se unió con otro de forma triangular. 
El tablero del juego consta de 18 casillas (contado las casillas de meta y salida) en las cuales se pueden elegir las pruebas por medio del azar a través de unas "minitarjetas" escondidas dentro de unas bolsa opacas. Las tarjetas pequeñas están construidas con cartulinas y papel donde esta dibujado el símbolo de cada prueba.

Se seleccionaron las fotografías de animales de cada ecosistema y se fotocopiaron a color para realizar con ellas las distintas pruebas. Para realizar los puzles las imágenes se pusieron a la mitad del tamaño de A4 y se recortaron en cuatro trozos. Para la prueba de emparejar, las imágenes se imprimieron también a color pero el tamaño varió entre $8 \mathrm{~cm} \times 13 \mathrm{~cm}$ y $7 \mathrm{~cm} \times 9 \mathrm{~cm}$.

Para la pruebas de imitar animales, sería la misma guía del juego quien eligiese que animal a imitar. Se escogieron huellas de dos animales de cada uno de los hábitats. En la prueba de alimentación se escogen tres imágenes de tres animales de distintos hábitats $\mathrm{y}$, por otro lado, se muestra una imagen de otro animal y los jugadores deben razonar de qué animal de los tres primeros podría ser presa el último mostrado, por lo que deben observar las características de los animales para superar la prueba.

\section{FICHAS TÉCNICA Y DIDÁCTICA DEL JUEGO}

En las Tablas 1 y 2 se recogen las características del juego diseñado y elaborado. Ambas constituyen fichas que podrían emplearse en el archivo de una ludoteca, en la que se dispusiera de este recurso lúdico.

\begin{tabular}{|l|l|}
\hline & Tabla 1. Ficha técnica del juego Ecomundi \\
\hline 1 Número de orden (en una ludoteca se numeran por orden de llegada):1 \\
y fotografías del juego
\end{tabular}




\begin{tabular}{|c|c|}
\hline \multicolumn{2}{|r|}{ Tabla 2. Ficha didáctica del juego Ecomundi } \\
\hline Nombre del juego & \begin{tabular}{|r|} 
\\
Ecomundi
\end{tabular} \\
\hline Piezas y material: descripción & $\begin{array}{l}\text { Goma eva, cartón piedra, cartulina, fieltro, fotografías en papel y velcro y } \\
\text { recursos electrónicos (fotos de los animales en un Word) }\end{array}$ \\
\hline Lugar de fabricación & España \\
\hline Homologación [Sí, en qué país(es): /No] & No \\
\hline $\begin{array}{l}\text { Cualidades intrínsecas de las piezas: formas } \\
\text { y color, material del que están hechas }\end{array}$ & $\begin{array}{l}\text { Rectangulares: el tablero y la carretera. } \\
\text { Cuadrada para las fotos y para la cartulinas } \\
\text { Redondas, las dunas del desierto del tablero. } \\
\text { Onduladas: adorno del tablero el río. }\end{array}$ \\
\hline Cualidades relativas de las piezas: tamaños, & Grande (tablero), mediano (puzles) y pequeño (fotografías y "mini-tarjetas") \\
\hline Dinámica del juego y reglas: explicación & $\begin{array}{l}\text { 1. Iniciar en la casilla de salida, el primer equipo que sale es por medio del } \\
\text { 2. } \text { juego de azar. } \\
\text { 3. Cuananzaran las casillas aunque el equipo gane o pierda la prueba. } \\
\text { cualquiera de ellas, las pruebas estarán ligadas a los animales o plantas } \\
\text { que le correspondan con la zona del juego. } \\
\text { 4. El equipo que gana es el que consigue más pruebas. } \\
\text { 5. Las } 6 \text { pruebas que hay son elegidas por medio de las "mini-tarjetas". } \\
6 \text { En el juego habrá dos equipos con tres miembros y un guía que ayudara en } \\
\text { casos puntuales, dando pistas. } \\
\text { Las pruebas son de cuatro tipos } \\
\rightarrow \text { Puzles de animales. } \\
\rightarrow \quad \text { Emparejamiento de animales (adultos y crías de cada especie). } \\
\rightarrow \quad \text { Imitación de los sonidos o movimientos de los animales (indicado por la } \\
\rightarrow \quad \text { guía). } \\
\rightarrow \quad \text { ¿ué come este animal? }\end{array}$ \\
\hline $\begin{array}{l}\text { Peligrosidad/riesgos (en las piezas o en su } \\
\text { uso) }\end{array}$ & Se pueden tragar las piezas "mini-tarjetas" si fueran demasiado pequeñas \\
\hline Tiempo de preparación & Mediano \\
\hline Duración [corta/media/larga] & Larga \\
\hline$N^{0}$ de jugadores & Dos equipos de 3 personas \\
\hline Edad preferente de los jugadores & 4 a 6 años \\
\hline De uso en interior/exterior & Interior \\
\hline $\begin{array}{l}\text { Tipos de acciones de los jugadores } \\
\text { primordialmente (físicas, mentales, ambas) }\end{array}$ & Ambas \\
\hline Sentidos que se utilizan & Vista y oído \\
\hline $\begin{array}{l}\text { Habilidades/capacidades o destrezas que } \\
\text { favorece (psicomotrices, cognitivas...) }\end{array}$ & $\begin{array}{l}\text { Psicomotrices: control postural, conocimiento del cuerpo, orientación espacial y } \\
\text { motricidad fina. } \\
\text { Cognitivas: lógica, orientación } \\
\text { Social: interacción con los compañeros del grupo o los contrincantes, } \\
\text { Expresión oral: turnos de palabra }\end{array}$ \\
\hline Objetivos propios del juego & $\begin{array}{l}\text { Trabajar en equipo. } \\
\text { Aprender por medio del ensayo y error. } \\
\text { Mejorar la capacidad de atención y concentración. Reconocer los animales y } \\
\text { plantas de distintos ecosistemas. } \\
\text { Conocer los tipos de alimentos que comen los animales. } \\
\text { Establecer relaciones lógicas entre crías y adultos. } \\
\text { Iniciar conocimiento de la cadena alimenticia de los animales. }\end{array}$ \\
\hline Coste económico (estimado o conocido) & $30 €$ \\
\hline Contenidos científicos & $\begin{array}{l}\text { Relaciones lógicas, emparejamientos,, ecosistemas, hábitats, cadena alimenticia, } \\
\text { plantas, animales, crías y adultos, huellas de animales. }\end{array}$ \\
\hline Autocorrección [Sí, de qué forma:... /No] & $\begin{array}{l}\text { Si en algunos pruebas como el puzle o emparejamiento, las demás necesitan } \\
\text { ayuda del guía. }\end{array}$ \\
\hline $\begin{array}{l}\text { Universalidad en sus reglas: puede ser } \\
\text { comprendido sin explicaciones [Si/No] }\end{array}$ & No \\
\hline $\begin{array}{l}\text { Fundamentación teórica (autores en los que } \\
\text { se basa) }\end{array}$ & Montessori (1964) \\
\hline
\end{tabular}

\section{Reflexión final}

Este trabajo ha supuesto una oportunidad para profundizar en el diseño y la elaboración de recursos lúdicos especialmente destinados a la enseñanza de las ciencias en Educación Infantil. 


\section{Agradecimientos}

Al Secretariado de Innovación Docente del Vicerrectorado de Ordenación Académica y Profesorado de la Universidad de Granada (España), por conceder el Proyecto de Innovación Docente 2013-2016.

\section{Referencias}

Fernández-Oliveras, A. y Oliveras, M. L. (2014a). Playing for science and mathematics education: an experience for pre-service kindergarten teacher training. En Costa M. F. M., Pombo P., Dorrío B.V. (Eds.), Hands-on Science. Science Education with and for Society (180 -183). Braga: Hands-on Science Network.

Fernández-Oliveras, A. y Oliveras, M. L. (2014b). Pre-service kindergarten teachers' conceptions of play, science, mathematics, and education. Procedia-Social and Behavioral Sciences, 152, 856-861. DOI:10.1016/j.sbspro.2014.09.334.

Fernández-Oliveras, A. y Oliveras, M. L. (2015). Conceptions of science, mathematics, and education of prospective kindergarten teachers in a play-based training. International Journal on Advances in Education Research, 2(1), 37-48.

Marín Santaolaya, A. y Romero Rodríguez, J.M. (2013). Un centro lúdico como refuerzo educativo en período vacacional, dirigido a niños de 5-12 años. ReiDoCrea,2,149-156.

Montessori M. (1964). The Montessori Method. Nueva York: Schocken Books. 